\title{
Ten years of photonics education at the college level in Ontario: results and by-products
}

\section{Marc Nantel}

Marc Nantel, "Ten years of photonics education at the college level in Ontario: results and by-products," Proc. SPIE 7783, Optics Education and Outreach, 77830P (31 August 2010); doi: 10.1117/12.861404

SPIE Event: SPIE Optical Engineering + Applications, 2010, San Diego, California, United States 


\title{
Ten years of photonics education at the college level in Ontario: Results and by-products
}

\author{
Marc Nantel \\ ${ }^{a}$ Ontario Centres of Excellence, 2655 North Sheridan Way, Mississauga, ON, Canada, L5K 2P8
}

\begin{abstract}
In 2000, there was no way for an Ontario student to obtain a credential in optics, laser or photonics without going through graduate school. This was in, arguably, the world-leading jurisdiction in photonics-enabled telecommunications industry. To alleviate this problem and supply the job market with highly-qualified people in the field of optics and photonics, the Ontario Centres of Excellence - then as Photonics Research Ontario - partnered with Algonquin College (Ottawa) and Niagara College (Welland) to establish over the past decade a suite of programs: a 1-year Certificate in Advanced Lasers, a 2-year Diploma for Photonics Engineering Technician, a 3-year Diploma for Photonics Engineering Technologists and a 4-year Bachelor of Applied Technology - Photonics. Much has been learnt along the way - the crucial need for industrial partner and government support, for example - and many course corrections had to be made (telecom bust, anyone?). The author will share the results of this 10-year journey so far, the lessons learnt, and a view to the next ten years for these programs and photonics education in Ontario in general.
\end{abstract}

Keywords: Photonics education, optics, colleges, technician, technologist, bachelor's, Ontario, networking

\section{INTRODUCTION}

In the late 1990s, there were few regions in the world ready to handle the extra demand in personnel qualified in optics, lasers and photonics that would soon be unleashed by the increased demand put on the field by the growth of the telecom sector. Places like Rochester, NY, USA, with its extensive programs in optics at the University of Rochester, the Rochester Institute of Technology and Monroe Community College, were already serving an active local population of companies like Eastman-Kodak, Xerox and Corning. They had the programs in place to cover all needs in photonics, from technicians to PhDs. Québec City, QC, Canada, was another such place, with photonics programs at Université Laval and several colleges in the area. Europe, Asia and Australia also had similar pockets, to varying degree of development.

Ontario was not ready, despite being the largest province in Canada and the centre of much of the country's photonics innovation and industry. Most of the province's available photonics education programs worked toward producing Master's and PhD-level scientists, through world-class photonics research programs at national laboratories and universities. Physics, Chemistry and Engineering department offered courses in optics as part of their curriculum, but there were no undergraduate programs leading to a credential in photonics. In most cases, one had to get to graduate school before working with optics meaningfully. This was generally not seen as a problem until the pressures of the demand for a strongly photonics-enabled workforce began to be more keenly felt

In Ontario, home of Nortel Networks, JDS Uniphase, Lumonics and other photonics giants at the time, this increased demand for a qualified workforce became the limiting factor for growth in a highly-strategic industry. There were too few photonics experts coming out of Ontario's educational institutions and, in the majority of cases, those were overqualified. There was an urgent need for assemblers, technicians and engineers with photonics knowledge to design, build, package, test, sell and service all these products, not just MSc and PhD researchers to invent them.

In 1999, at the height of this photonics frenzy, the Ontario Centres of Excellence (OCE, then known partly as Photonics Research Ontario) set out a plan to address the need for photonics personnel in its entirety, to relieve this bottleneck and allow for growth in the sector, with an emphasis on community colleges and the need for technical staff [1,2]. This paper summarizes the last ten years of photonics education at colleges in Ontario, with attending successes and pitfalls. 


\section{THE PLAN FOR PHOTONICS EDUCATION IN ONTARIO}

There was a fertile ground in Ontario for a strong photonics education plan to take root and blossom. The education system in Canada is ideally suited for post-secondary education, as shown in figure 1, representing the state of the OECD countries educational attainment in post-secondary - university and college - in the labour force, for year 2000 data [3]. One can see that Canada was first in the measured countries, with $44 \%$ of its working population to have completed at least one credential at the post-secondary level.

The problem is that very few of these workers had seen photonics when studying. In fact, as shown in figure 2 , the education pyramid for photonics in Ontario, circa 2000, showed that very little of it covered the field of photonics. There was a dearth of programs other than $\mathrm{PhD}$ and master's, and also a severe lack of photonics awareness and outreach to the community and K-12 children. Similarly - or put in a different way - the pathways in photonics education were limited and limiting, as illustrated in figure 3. While one ought to be able to choose to access a career in photonics through both college and university paths, only the latter was open and only at the graduate-studies level; for someone already in the workforce, the options were even more limited. All this resulted in a workforce not well prepared to satisfy the strong demand that photonics companies had for qualified personnel - those making photonics and those using it in their products and applications. Large companies like JDS Uniphase, Nortel Network, Lucent Technologies, Corning, Alcatel and GSI Lumonics were in dire need for personnel at all levels, from assemblers to technicians to engineers and research scientists. This human resource crisis was only exacerbated by an increasing number of start-up companies with staggering growth, most of which were well funded by the venture capital community. These start-ups were in desperate need of R \& D scientists to bring their new products to market and establish themselves before their next round of financing. Add to this the increasing use of photonics in other industries like automotive, biomedical, manufacturing, etc., and one was faced with a bottleneck to the growth of the sector resting on the availability of highlytrained photonics personnel.

To address this, the Ontario Centres and Excellence and its partners decided simply to fill the pyramid and the pathway as best as it could; to give Ontario photonics education and training from grade school to grad school $[1,2]$.

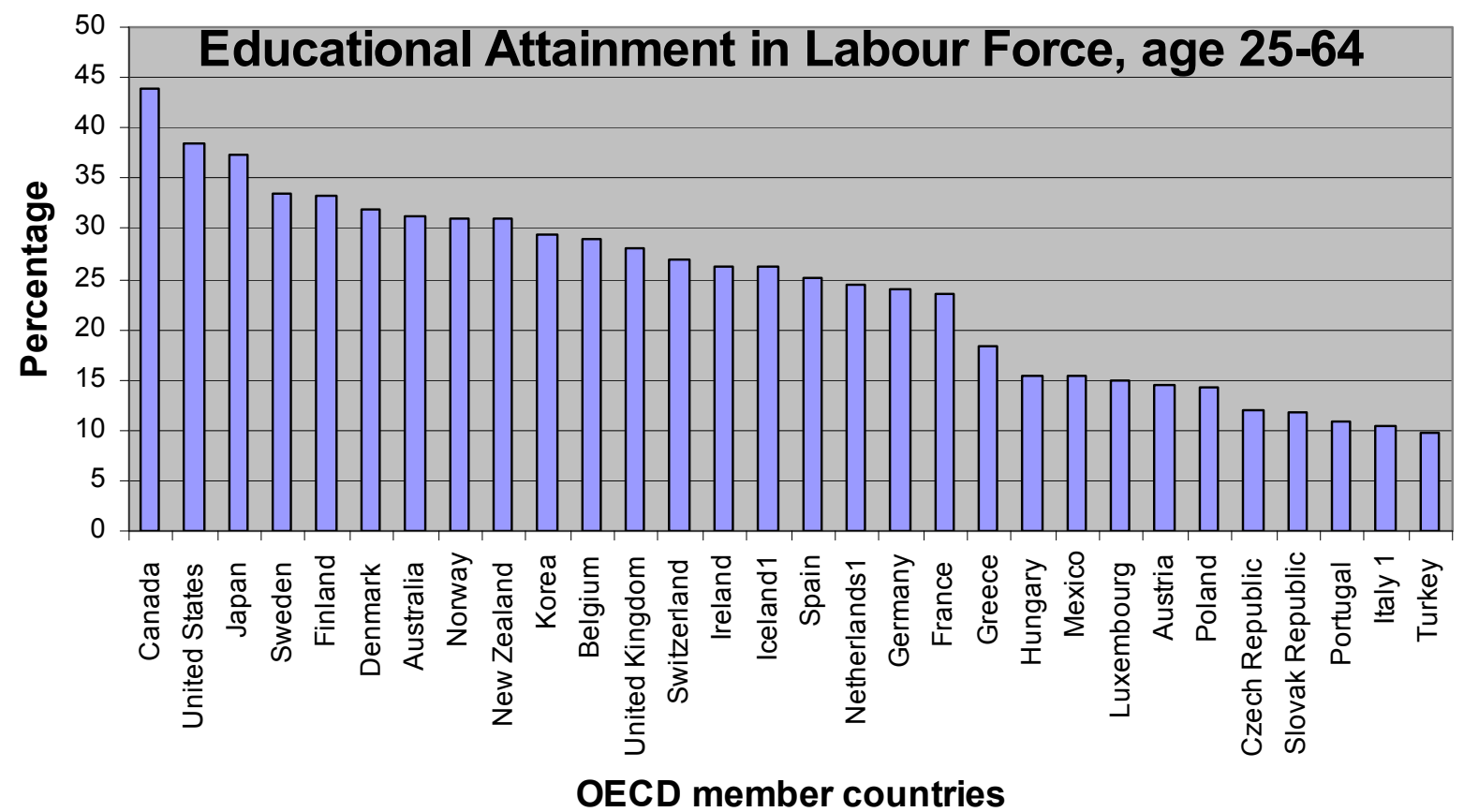

Figure 1. Percentage of the working population, age 25 to 64 , with at least one credential at the post-secondary level in the OECD countries, circa 2000 (adapted from Higher Education and Adult Learning, Education at a Glance 2002, OECD (2002)). 


\section{Work Force Credential Educational Institution}

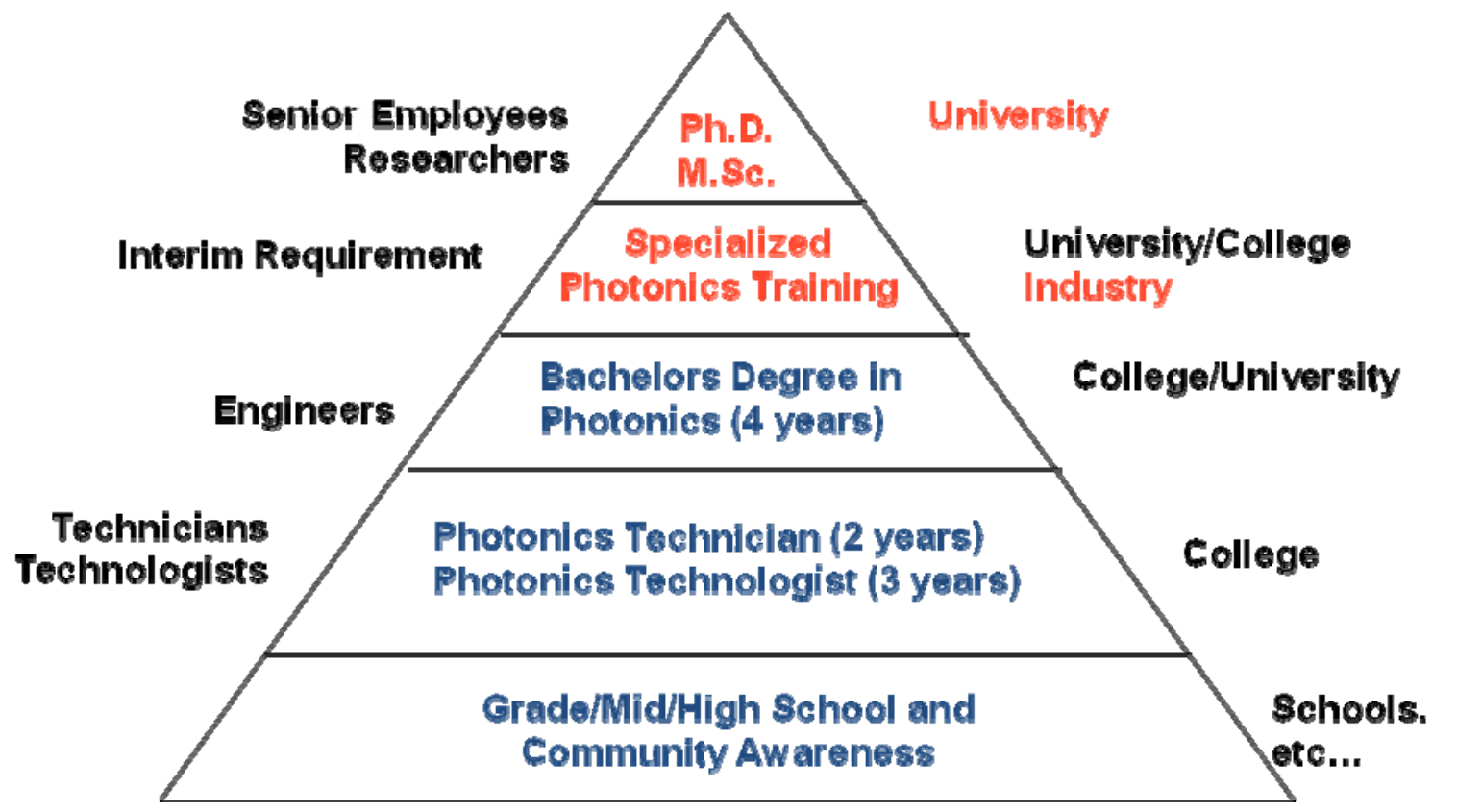

Figure 2. In 2000, the only photonics credentials one could obtain in Ontario were at the $\mathrm{PhD}$ and master's levels, and through rare industry-specific training courses (the top two layers of the pyramid).

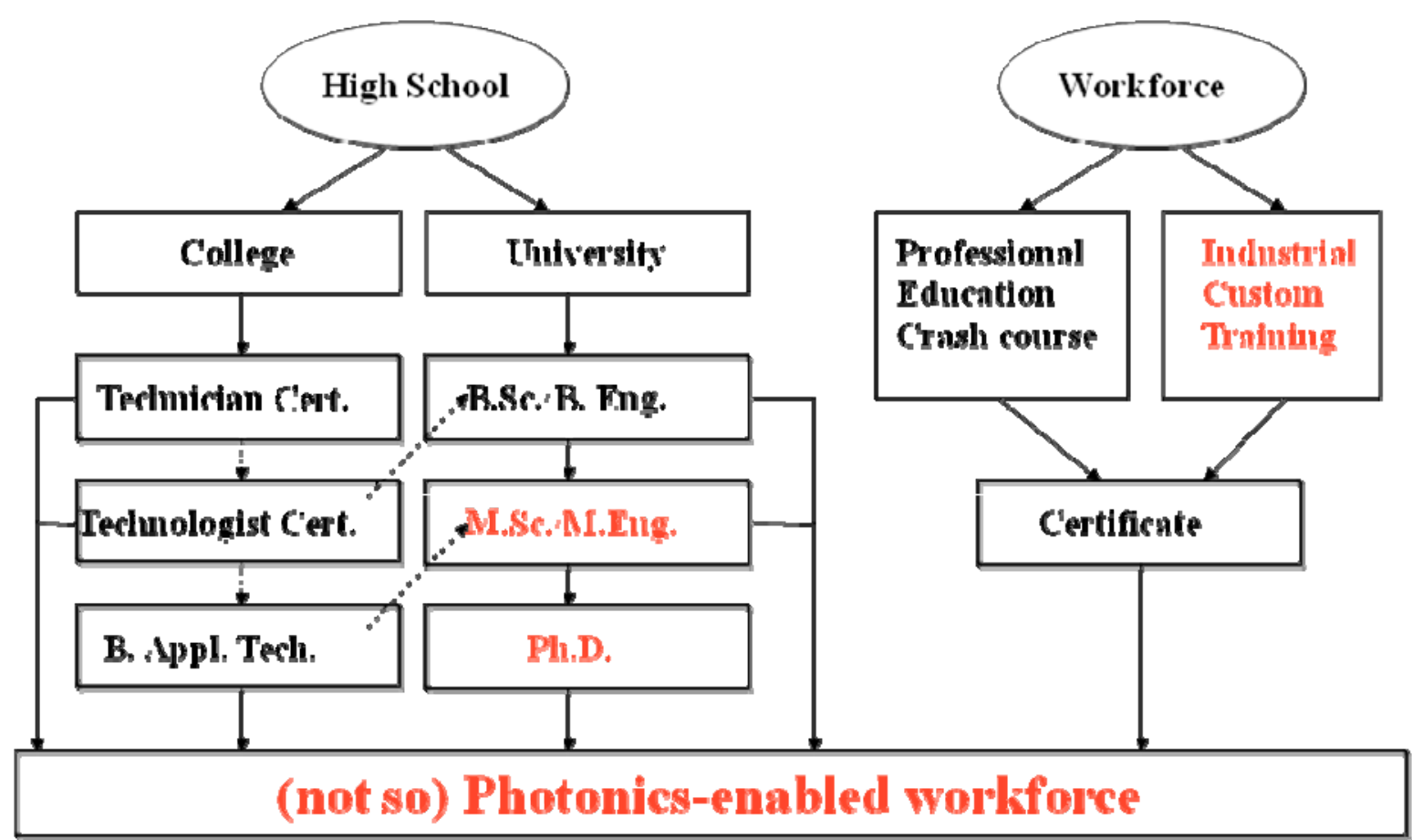

Figure 3. In 2000, the pathways in photonics education in Ontario were limited and limiting, resulting in a photonics-poor workforce. 


\section{PHOTONICS EDUCATION AND TRAINING AT ONTARIO COLLEGES}

In an effort to provide the fastest and most effective response to industry's needs, it was decided to first tackle the need for photonics technicians and technologists. There were many factors entering this decision. While focusing on photonics awareness and K-12 might help with the provision of fresh photonics-hungry minds, the time lag between steering a young student into photonics and his/her graduation to the workplace was simply too long to address the immediate crisis. Also, if nothing was done to provide said youngsters with photonics programs at the undergraduate level, the same problem of having to plow through graduate schools to see any amount of optics and photonics would remain (with the attending 3-6 extra years of delay, to boot). A photonics engineering degree at the university level was contemplated, but here too, time was the enemy. In order to create such a program from scratch, pass it through the academic and administrative hoops of the university - nothing to say of ABET's - would also take too long.

This is why OCE concentrated its efforts on the province's excellent community colleges. They are generally more in tune with industry's needs and make it their mission to address them as quickly as possible since their main mission is to educate and train students for the workforce in industry. Indeed, every program at the colleges has an industry advisory committee to guide it on the requirements of employers and the quality of its offerings.

Two particular colleges that held promise for the implementation of photonics programs were Algonquin College (in Ottawa, at the epicenter of the telecom storm) and Niagara College (in Welland, where manufacturing was a major going concern). By choosing to work with both colleges, the goal was to bring photonics education and training not only to the optical-fibre and telecom sector, but also to advanced manufacturing, biomedical applications, imaging and more.

\subsection{Technical Diplomas}

There was available at the turn of the century a fund at the Ontario Ministry of Economic Development and Trade (MEDT) to support, in collaboration with industry, the establishment of education and training program to address strategic skills gaps in the province's workforce (the aptly-named Strategic Skills Investment program, or SSI). OCE, Niagara College and Algonquin College teamed up with 21 industry partners and successfully obtained funding for a 4year, \$7.6-million project to install at both colleges 2-year photonics technician and 3-year photonics technologist programs $[1,2]$. Details of the journey to these programs can be found in the references; tables 1 and 2 show the curriculum for the 2-year and 3-year programs, respectively.

Table 1. Curriculum for the 2-year Photonics Engineering Technician program at Niagara and Algonquin College, as designed in 2000-2001; "Tn" refers to "Technician".

\section{First Year}

Programming

Electronic Fundamentals Tn

Applied Communication

Algebra I Tn

Algebra II Tn

Trends in Photonics Tech

Optics/Optical Fibre Principles Tn

Optics and Wave Tn

Kinematics/Dynamics Tn

Occupational Health \& Safety
Second Year

Interfacing

Semiconductors \& Logic Tn

Telecommunications Tn

Statistics Tn

Fundamentals of Light Sources Tn

Optic/Optical Fibre Devices Tn

Laser Systems Tn

Manufacturing Photonics Components

Photonics Manufacturing Systems Tn

Two Education Electives 
Table 2. Curriculum for the 3-year Photonics Engineering Technologist program at Niagara and Algonquin College, as designed in 2000-2001; "Ty" refers to "Technology".

\begin{tabular}{|c|c|c|}
\hline First Year & Second Year & Third Year \\
\hline Programming & Interfacing & Technical Communications \\
\hline Electronic Fundamentals Ty & Semiconductors \& Logic Ty & Control Systems \\
\hline Applied communications & Telecommunications Ty & Photonics Man. Systems Ty \\
\hline Algebra Ty & Statistics Ty & Advanced Opt.Systems Ty \\
\hline Intro. to Calculus Ty & Integration \& Apps Ty & Opto-Electronic Devices Ty \\
\hline Trends in Photonics Tech & Diff Eqn Ty & Image/Signal Processing Ty \\
\hline $\begin{array}{l}\text { Optics/Optical Fibre } \\
\text { Principles Ty }\end{array}$ & Fund. of Light Sources Ty & Laser-Matter Interactions Ty \\
\hline Optics \& Wave Ty & Optics/Fibre Devices Ty & Photonics Res. Project Ty \\
\hline Kinematics/Dynamics Ty & Laser Systems Ty & Fluid \&Vacuum Systems Ty \\
\hline \multirow[t]{2}{*}{$\begin{array}{l}\text { Occupational Healthy \& } \\
\text { Safety }\end{array}$} & $\begin{array}{l}\text { Manufacturing Photonics } \\
\text { Components Ty }\end{array}$ & Heat Transfer Ty \\
\hline & 2 Education Electives & 2 Education Electives \\
\hline
\end{tabular}

\subsection{Bachelor's degrees}

In 2002, the Province of Ontario revised the law concerning its community colleges to include applied research and bachelor's degrees to their mandate. This decision opened up many opportunities for the colleges in the province. OCE and its partners at Algonquin College and Niagara College saw right away the chance to build on their first successes, and to add photonics to yet another layer of the pyramid and more boxes in the photonics education pathway.

Going once again to the well, the three partners and their industry supporters secured funding from the MEDT-SSI program, this time for a 4-year, \$9.6-million project to establish at both colleges a Bachelor of Applied Technology Photonics, or BAT - Photonics. Strong with its now 35 industrial partners and the experience of the still-ongoing technician/technologist project, and brand-new curriculum for a 4-year bachelor's degree was designed and implemented. Tables 3 shows the curriculum for the 4-year Bachelor of Applied Technology - Photonics. Of note, since this was the first time that a college could offer such a degree, was that the approach taken was uniquely collegelike: the most hands-on courses and labs were written into the early years of the program to give the students a feel for the physical phenomena they were studying, with the more theoretical treatments of the effects presented in the fourth year. This program followed the coop model, with three paid work terms giving the students a good taste of what it is like to work in industry before they graduate. Details of the journey to this program can be found in the references [4, 5]. At roughly the same time, there were two other undergraduate degrees starting in Ontario: the Honours' Physics Degree in Photonics at Wilfrid Laurier University (Waterloo) and the Photonics Engineering Degree at McMaster University (Hamilton) $[4,5]$. The former is still available, while the latter did not survive in its original form, on the basis that it was too similar to the university's already strong Engineering Physics program; photonics still thrives at McMaster Engineering through several option courses in photonics, optoelectronics and biophotonics that can be grouped together to form a photonics engineering "stream" within the Engineering Physics program. 
Table 3. Curriculum for the Bachelor of Applied Technology at Algonquin College and Niagara College, as designed in 2003-04. In italics are the course in mathematics and computing, in underlined are the physics courses and in bold are the courses particular to optics and photonics; the electives and other non-specialized courses are in normal type.

\begin{tabular}{|c|c|c|}
\hline & Fall Term & Winter Term \\
\hline \multirow[t]{7}{*}{ Year 1} & Calculus I & Calculus II \\
\hline & Programming I & Programming II \\
\hline & General Chemistry & Kinetics \& Dynamics \\
\hline & Optics \& Waves & Electro-Technology \\
\hline & Trends in Photonics Technologies & Optics/Fibre-Optics Principles \\
\hline & Occupational Health/Safety and Ethics & \\
\hline & Fall Term & Winter Term \\
\hline \multirow[t]{6}{*}{ Year 2} & Linear Algebra & Differential Equations \\
\hline & Interfacing Semiconductors \& Logic & Statistics \\
\hline & Fundamentals of Light Sources & Laser Systems \\
\hline & Optics/Fibre-Optics Devices & Telecommunications \\
\hline & Elective & Manufacturing Photonics Components \\
\hline & & Technical Communication \\
\hline \multirow[t]{2}{*}{ Coop Term } & Summer of Year 2 & \\
\hline & Fall Term & Summer Term \\
\hline \multirow[t]{6}{*}{ Year 3} & Control Systems & Advanced Calculus \\
\hline & $\underline{\text { Thin-Film and Vacuum Systems }}$ & Electromagnetic Theory \\
\hline & Advanced Optics Systems & Opto-Electronics Devices \\
\hline & Photonics Manufacturing Systems & Imaging/Image Signal Processing \\
\hline & Elective & Business Principles \\
\hline & & Elective \\
\hline Coop Term & Winter of Year 3 & \\
\hline \multirow[t]{7}{*}{ Year 4} & Winter Term & Summer Term \\
\hline & $\underline{\text { Material Science }}$ & $\underline{\text { Solid-State Physics }}$ \\
\hline & $\underline{\text { Quantum Physics }}$ & Biomedical Photonics \\
\hline & Thermodynamics \& Heat Transfer & Advanced Research Project \\
\hline & Advanced Optical Theory & Operations Management \\
\hline & Photonics Research Project & Elective \\
\hline & Elective & \\
\hline Coop Term & Fall of Year 4 & \\
\hline
\end{tabular}




\subsection{The programs' student outputs}

With these three programs - 2-year Technician, 3-year Technologist and 4-year Bachelor's in photonics - a large chunk of the "photonics from grade school to grad school" plan was in place. Along the way, much outreach effort was also conducted to recruit students into the new programs and industry courses were offered by the colleges to the companies that needed it, thereby covering some more of the photonics education pyramid and pahtways. Table 4 shows the student outputs of the three programs - both colleges confounded - by year.

The first students started in Fall 2000 at Algonquin College, in Corporate/Contract Training and Continuing Education. They were employees of Ottawa telecom firms needing training in fibre-optics handling and splicing; the companies had pressed strongly for the programs to be available as soon as possible. The faculty at both colleges raced to get some of the new equipment in place to allow the possibility of such training before the full curriculum design had been completed, in order to respond to the industry demand. Already in the first year, the project graduated 135 photonicsenabled personnel from these specialized courses.

The first cohort for the Diploma programs (2-year Technician and 3-year Technologist) entered in Fall 2001. Niagara College elected to advertise both 2-year and 3-year programs from the beginning, whereas Algonquin College expected only a strong demand for the 3-year program. In fact, Niagara's first Technician cohort was convinced to start in the Technology program for lack of critical mass (there were only 7), hence all 77 Diploma students for the academic year 2001/02 entered into the Technologist program; 52 continued on to the second year, for an attrition rate of $32 \%$. While this rate can seem high, it is typical of such new programs, especially those as demanding mathematically as the photonics programs. There was a marked decrease in the registration for the Corporate/Contract Training and Continuing Education as the telecom bust started to take hold of the corporate customers for such courses.

Table 4. Student graduating from the Niagara College and Algonquin College photonics programs. Year 2000-01 was spent developing the curriculum for the Technician and Technologist programs, with entry classes in Fall 2001, all in the 3-year Technologist; Fall 2002 saw the first real Technician program students entries, as the three Technicians to graduate in Spring 2003 were early-exit Technologists, ending after two years (retroactively considered to have entered the technician stream in Fall 2001). Year 2003-04 was spent developing the BAT-Photonics curriculum, with entry classes in Fall 2004.

\begin{tabular}{|l|l|l|l|l|}
\hline & Technicians & Technologists & BAT-Photonics & Others \\
\hline $2000-01$ & & & & 135 \\
\hline $2001-02$ & First entrants & First entrants & & 62 \\
\hline $2002-03$ & 3 & & & 290 \\
\hline $2003-04$ & 10 & 30 & First entrants & 7 \\
\hline $2004-05$ & 6 & 20 & & 0 \\
\hline $2005-06$ & 7 & 17 & & 0 \\
\hline $2006-07$ & 6 & 24 & 16 & 0 \\
\hline $2007-08$ & 6 & 7 & 8 & 4 \\
\hline $2008-09$ & 0 & 7 & 6 & 0 \\
\hline $2009-10$ & 1 & 22 & 30 & 639 \\
\hline Totals & 39 & 127 & & 0 \\
\hline
\end{tabular}


In Fall 2002, Niagara elected to offer the Technician program with 9 entering students and one year-2 student transfer from the 3-year program; at the end of the year, the first graduates from the 2-year programs were in fact 3 Technicians from Niagara who finished in Spring 2003 (early exits from the 3-year programs who were snatched up by the workplace immediately). The Technologist program continued in its success, recruiting 80-new students in Year 1 for its second cohort. The high number of "other" students comes mostly from enrolment in the increasingly popular "Trends in Photonics Technology" general education course.

In Fall 2003, the bad news from the telecom industry caught up with the Diploma programs, showing a marked decrease in students entering both programs. Nevertheless, 40 students graduated from these programs in Spring 2004, 10 with a Technician Diploma and 30 with a Technologist Diploma. A survey of the Niagara College students graduating from this cohort returned that, 6 months after graduation, $71 \%$ of the Technicians were employed (57\% in photonics) and that $100 \%$ of the Technologists were employed (50\% in photonics). Again, Continuing Education showed interesting numbers from the "Trends in Photonics Technologies" course.

The first BAT - Photonics student cohort started in Fall 2004 with 34 students, with the 2-year and 3-year programs continuing alongside. Of those 34, 23 came back for Year 2 in Fall 2005, accompanied by a second cohort of 39 entering Year 1. The relatively heavy attrition rate from Year 1 to Year 2 can be attributed to the rigorous bachelor's curriculum possibly surprising college students. In Fall 2006, 17 of the 23 students from the first cohort came back, for a better retention rate; 27 of the 39 students from the second cohort returned and a third cohort of 14 entered Year 1 . The reason for the sharp decrease in Year 1 enrolment is that Niagara College suspended its BAT - Photonics after the two first cohorts, based on a low demand and an inability to offer the program in a financially viable way. Niagara College did not pursue the renewal of its right to offer the program; all new entries were at Algonquin College. In Fall 2007, 12 of the final year students returned and 10 graduated (6 at Niagara and 4 at Algonquin) in Spring 2008; 21 of 27 continued in Year 3, 10 of 14 persevered with Year 2 and the fourth cohort clocked in at 15, all at Algonquin college.

Algonquin College has also elected to suspend its BAT - Photonics in Fall 2008; they did not have a Fall 2009 cohort either, preferring to concentrate on the 2-year and 3-year programs, like Niagara. It may be that the BAT - Photonics idea was ahead of its time or, more likely, behind the "telecom bust". It may take several years for the bad publicity from the early 2000s to dissipate and for the reality of photonics' vibrant job market in all fields - not just telecom - to hit home with parents and prospective students.

The Diploma programs have graduated 166 students since their inception, and the bachelor's program, 30. The author estimates that the photonics programs at Algonquin College and Niagara College (including Corporate/Contract, Continuing and Certificate) have increased the number of photonics-enabled people in Ontario - people who have taken at least one full course, and most having gone at least one year through one of the program - by more than 1,250, so far.

\section{THE ONTARIO PHOTONICS EDUCATION AND TRAINING ASSOCIATION}

While OCE was concentrating on the college level, many other photonics education programs were trying to emerge in Ontario: Vitesse (Re-Skilling) Canada (Ottawa), the Canadian Microelectronics Corporation (Kingston), the University of Toronto's Professional Development Centre (Toronto), the University of Waterloo's epSTAR (Waterloo) and Algonquin College were starting continuing education programs to provide photonics training for scientists and engineers already possessing degrees, to facilitate their slide into this sector with huge personnel demands. McMaster University (Hamilton), Carleton University (Ottawa) and Wilfrid Laurier University (Waterloo) were putting together new undergraduate degrees and specializations in photonics, as mentioned in the last section. Because of OCE's mandate to support the growth of photonics in the province, it was involved -- in one way or another -- with most of these new education and training programs.

All this activity featuring several new players in photonics education made for a rather confusing state of affairs from industry's and the student's points of view: "What are all these programs? Which one is best for my needs? What are the differences between them?" From the point of view of the educational institutions implementing the new offerings: "What are these other programs? Are they going to target the same student pool as ours? How are we in competition for funds and industry support?" In order to focus the various stakeholders on the main task at hand - providing highquality photonics workers to industry and good careers for photonics students - a "summit" of all known Ontario nongraduate program providers was called by the author for 6 June 2001. At this summit, participants from universities, colleges and independent curriculum providers exchanged information about their respective programs and networked extensively. It was quickly realized that each had much more in common than was thought, including the challenges of 
teacher and student recruitment, and access to resources and funds. A main point emphasized at the summit was the almost non-existent voice the photonics education and training community had in the spheres of politics and the general public. In light of all of this and the success of the summit, all participants agreed to form an association to pursue together the common goal of providing photonics education and training in Ontario. This is how the Ontario Photonics Education and Training Association, or OPETA, came to be [6, 7].

In the beginning, OPETA was little more than 14 people from 9 institutions, held together by a desire to establish healthy high-quality programs in photonics. Even as such, OPETA was the start of a photonics education "cluster". A cluster is a group of local companies, educational institutions and other stakeholders rallying around a particular sector of the economy or industry [8]. By pooling resources, a cluster can network, share best practices, influence local politics, and lobby municipal, provincial or federal levels of government. One of the essential aspects of a cluster is that it be local, regrouping members from within a 50 to $100-\mathrm{km}$ radius, typically (in OPETA's case, this is expanded to the whole of the province of Ontario). One of the main tenets of clustering is that competitors are better served working together for the growth of the whole of their sector; to increase the size of the sector for everybody instead of everyone individually solely trying to get a bigger piece it.

In the early days of OPETA, the author became the de facto Chair of the fledgling association, an appointment that has since been renewed three times and still holds. The Chair is the extent of the formal structure of the cluster: ad-hoc committees are struck for special purposes (organizing the Annual Meeting, distributing donations, etc.), and their makeup changes from one time to another to facilitate a wider involvement from the whole OPETA membership. OPETA received funding from the Ontario Ministry of Economics Development and Trade through the project that established the 2-year Technician and 3-year Technologist programs at Niagara and Algonquin Colleges. This funding amounted to about $\$ 20,000$ over 4 years, at OPETA's onset. While this financial support was helpful, an association like OPETA can operate successfully with almost no cash, counting on in-kind donations from its members (to host the meetings, the webpage, etc...).

The networking done through OPETA was instrumental in weaving a coherent fabric in Ontario's photonics education and training sphere. OPETA has seen bursts of activity when its membership - 69 members from 53 institutions, at last count - needed it, and was rather quiet in-between. A few of its successes include the transfer of more than \$5-million of equipment donations from JDS-Uniphase and Bookham to its member education institutions over years 2002-2004 and the organization of the 2007 ETOP conference in Ottawa. OPETA is still in existence today; its listserv is an effective communication tool to publicize conferences and events of interest to the membership.

\section{THE CURRENT SITUATION}

It is clear that the promising photonics world of 1999-2000 took a sharp turn downward during what has now become known as the "telecom bust". Most of the photonics programs that came into existence at the turn of the century were geared specifically to cater to industry's then voracious need for photonics-qualified personnel. Of course, all along, other subfield of photonics were growing too: advanced manufacturing (machine vision, laser cutting, welding, drilling and marking); biophotonics (in diagnostics and therapeutics); energy (solar cells and high-brighness LEDs); in consumer products (LCD displays, plasma-screen TV, DVDs and Blu-Ray). Nonetheless, the immense shock to the economy that accompanied the telecom downturn left a bad taste in the public's collective mouth and did much damage to recruitment into the photonics education and training programs, even though the jobs offers still much outstrip the pipeline of graduates coming out of current photonics programs.

As shown in table 4, the number of students graduating from the colleges' photonics programs has dwindled to the point where both colleges have suspended their bachelor's degree programs; there are too few students enrolling to keep the programs economically viable. In June 2010, Algonquin College even announced a plan to completely wind down all its photonics programs. Faculty and local industry champions are fighting to retain some amount of capability to allow for an eventual rebound. As part of that, Algonquin College is working to form a partnership with Carleton University on a joint photonics bachelor's degree, which would replace their now-defunct BAT - Photonics.

The programs at Niagara College are surviving, but it is a struggle to recruit students into them. Strategies to keep things going include making the 2-year and 3-year programs have as many common courses as possible, thereby wiping off most of the "Tn" and "Ty" distinction in the curriculum; the technology students merely take more advanced math and do one extra year of study. Niagara College has struck a partnership with Brock University for a 1-year Advanced Laser postgraduate certificate, whereby Brock physics students spend a year at Niagara College studying lasers before 
returning to Brock to finish their physics degree, graduating with two credentials; Niagara also takes in non-Brock students. The 2008-09 academic year was the first for which this program was available and it was well attended.

There are numerous other collateral successes of the ongoing college photonics education experiment:

a) In establishing a complete suite of photonics programs, both colleges had to upgrade their facilities, curriculum and professorial staff to reflect the higher level of education expected from this field. This generated much benefit for the colleges and their industry partners in the form of active applied research programs at both colleges, with several research grants OCE and other funding agencies. Through these research projects, the students at both colleges experienced a richer learning environment, the faculty participated in the generation of new knowledge and products, and Ontario companies have found solutions to some of their technical and engineering problems. The breadth of subjects researched spans telecom, optics, manufacturing, horticulture and others. It is fair to say that Algonquin College and Niagara College owe a great part of their status as research-heavy colleges to the two Strategic Skills Investment photonics education projects and their resultant programs.

b) The creation of the Ontario Photonics Education and Training Association (OPETA), with all the networking and multi-million dollar industrial donations it brought to the education institutions of the province. More donations keep coming to both colleges for their technologists/technicians programs, as new partnerships are created.

c) It provided the impetus for Ontario to host the "Education and Training in Optics and Photonics (ETOP) Conference", in June 2007. This international bi-annual gathering is the premier venue for photonics educators worldwide, and is supported by all the major international optics societies (SPIE, OSA, IEEE-LEOS, ICO). The author and OPETA won the bid to organize the conference and to co-locate it with Photonics North 2007, in Ottawa. The conference was a great success, with representation from educators from all continents (except Antarctica). A proceedings volume of the papers presented at the 3-day event are available by CD from the author and online at http://spie.org/etop/etop2007.html.

\section{CONCLUSION AND LESSONS LEARNT}

The past ten years have been quite the roller-coaster for Ontario on the photonics education front. From an alarm bell bringing all hands on deck to address industry's urgent and immense need in 1999-2001 to the floor falling from under the market's feet in 2002-2004 - though a good occasion to score excellent industry donations, as companies were shedding equipment they no longer needed - to the slow decline in recruitment success still being felt in 2010, the life of photonics education in Ontario feels more like that of a giant star going supernova than that of the stable, steady Sun.

Amongst the lessons learnt from this whole exercise:

- It is important to lay out a long-term vision in order to cover all the bases - the whole pyramid and educational pathways - if one wants to create a viable ecosystem for the long run. An enabling technology like photonics is not going to go away, and is growing every day. Some of the resilience the Ontario photonics education ecosystem has shown and is still showing now is due to this long-term vision.

- Money helps, and having funding mechanisms to feed the implementation of this long-term vision is crucial. OCE and its partners were fortunate to have the MEDT-SSI funds to set up the programs at the colleges, given the expenses involved.

- Answering industry's needs is important, but some foresight is also crucial. The efforts shown by the colleges in diversifying their offerings, conducting more applied research and collaborating with universities when the going got tough, helped them ride the worst of the downturn. Not many predicted the telecom downturn, but keeping a steady eye on the far horizon avoided undue panic. Once programs like these are shut down, they are expensive to start again.

- Industry partners and their donations - in cash, in kind and in time - were key to the success in establishing the programs. Without industry staff on the curriculum committees, the colleges would not have had as good a view of the skills companies wanted the programs' graduates to have; without their equipment donations, colleges would have had to buy everything and the labs would have been much the poorer.

- Networking is one of the most underrated, but most important, part of the equation. With OPETA bringing together the various players, handling the industry donations - not just to colleges, but to universities, private 
providers, STEM outreach organizations and more - and organizing events like its Annual Meeting and ETOP 2007, the community of photonics education and training in Ontario built strong bases for weathering the telecom downturn and hopefully profiting from the current, more gradual, growth.

The future of photonics education is hard to predict, as are most things. One aspect of photonics that has not helped it, as a field, is that it does not belong to any one sector of the economy: it is everywhere, an enabling technology. This makes it difficult to explain to parents and prospective students where the jobs are and why. Nanotechnology will likely suffer the same problem as it grows more prevalent. Maybe one needs to learn from the electronics and software sectors - two other enabling technologies that don't appear to suffer for that malaise. Electronics conjures up in people's minds a direct association with the consumer market - unlike photonics, erroneously - and software runs on every computer. The photonics community needs to publicize photonics' ubiquity more aggressively. As the pursuit of more efficient lighting fixtures or intelligent automobiles or powerful DVD/Blu-Ray systems continues to gradually capture the public's imagination, photonics' place in these innovations must be trumpeted. The author is hopeful that the next ten years of photonics education will follow a mirror curve from the past ten: starting well enough, but finishing strong and climbing.

\section{REFERENCES}

[1] M. Nantel and J. Beda, Photonics Education and Training in Ontario, Phys. Can. 58, 19 (2002).

[2] M. Nantel and J. Beda, Photonics education and training in Ontario, Canada: an integrated plan, SPIE Proc. 4588A (2001).

[3] Higher Education and Adult Learning, Education at a Glance 2002, OECD (2002).

[4] M. Nantel, J. Beda, T. Grevatt, B. Chebbi, P. Jessop, and S. Song, Three new undergraduate degrees in photonics in Ontario, Phys. Can. 60, 319 (2004).

[5] M. Nantel, J. Beda, P. Jessop and S. Song, Three new bachelors of photonics in Ontario, SPIE Proc. 5578E (2004).

[6] M. Nantel, On the importance of networking in physics education: multiple heads are better than one, Phys. Can. 61, 91 (2005).

[7] M. Nantel, OPETA and GPEN: models for local and global networking, SPIE Proc. 5578E (2004).

[8] M.E. Porter, Clusters and the New Economics of Competition, Harvard Business Review, Nov-Dec. 1998 (1998). 